\title{
The role of aggregate granulation on testing fracture properties of concrete
}

\author{
M. Słowik \\ Lublin University of Technology, Poland \\ m.slowik@pollub.pl, bttp://orcid.org/0000-0001-9627-3625
}

\begin{abstract}
Concrete is a porous material containing aggregate of different sizes, hardened cement matrix with air pores, microcracks and water. Concrete internal structure is different from that of other engineering materials. Furthermore concrete is described as quazi-brittle material. Fracture processes in it form in a way that does not fit within classical theories. Therefore, to describe failure of concrete structures nonlinear fracture mechanics is often applied with success. Basic concrete parameters, like compressive and tensile strength, and modulus of elasticity, are not enough to analyze fracture processes in concrete structures. Additional fracture properties should be tested, among them fracture energy, complete diagram of stress-deformation under axial tension and the width of fracture process zone. Recognizing and testing fracture parameters is of paramount importance when analysing fracture process in concrete structures. The correct data of material's properties and the adequate fracture model applied in numerical simulations influence final results. In the paper the findings reported in the professional literature are summarized and obtained results of the own numerical simulation are reported in order to give a deeper knowledge on the role of aggregate on fracture properties of concrete.
\end{abstract}

OPEN ACCESS

Citation: Słowik, M., The role of aggregate granulation on testing fracture properties of concrete, Frattura ed Integrità Strutturale, 58 (2021) 376-385.

Received: 18.08 .2021

Accepted: 29.08.2021

Published: 01.10.2021

Copyright: (C) 2021 This is an open access article under the terms of the CC-BY 4.0, which permits unrestricted use, distribution, and reproduction in any medium, provided the original author and source are credited.

KEYWORDS. Concrete; Fracture process; Aggregate.

\section{INTRODUCTION}

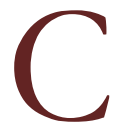
oncrete is a porous material containing aggregates, hardened cement paste and water. Its internal structure is entirely different from that of other engineering materials. The maximum size of the aggregate can fall between 10 to $32 \mathrm{~mm}$ for structural applications and thus, the dimensions of the areas where fracture processes nucleate and develop are comparable with the size of normal structures.

Aggregates constitute the bulk of the concrete. They comprise $60-80 \%$ of the volume of the concrete and have to be so graded that the whole mass of concrete acts as a relatively solid, homogeneous, dense combination, with the smaller sizes acting as an inert filler of the voids that exist between the large particles. However, the concrete, as a structural material, 
has not a closed structure. Besides of entrained air porosity, concrete is intensely micro-cracked before loading. All these facts significantly influence concrete properties.

Concrete is usually described as a quasi-brittle material. For most of structural engineering applications, concrete needs to be reinforced because its tensile strength is only around one tenth of its compressive strength.

In order to obtain the basic characteristic of concrete as a constructional material the following parameters should be known:

- compressive strength of the concrete $\left(f_{c}\right)$,

- tensile strength of the concrete $\left(f_{c t}\right)$,

- modulus of elasticity $\left(E_{c m}\right)$,

- Poisson's ratio,

- coefficient of thermal expansion.

However these parameters are not enough to deeper analyze failure in concrete structures. Fracture processes in concrete form in a way that does not fit within classical theories. Therefore to describe crack propagation in concrete, nonlinear fracture mechanics can be applied with success. Several models of concrete cracking were developed based on nonlinear fracture mechanics. One of them is a crack band model of tensile concrete which was proposed by Hillerborg, Modeer, Petersson [1] - see Fig. 1. The crack starts to propagate when the stress at the crack tip reaches the tensile strength $f_{c t m}$. The stress does not fall to zero at once but it decreases with increasing crack width and it reaches zero when crack width is $w_{1}$. For that part of the crack where $w<w_{1}$, there is a fracture process zone with some remaining ligaments, which allow to transfer stress. As these ligaments are to be overcome during opening the crack, energy is absorbed.

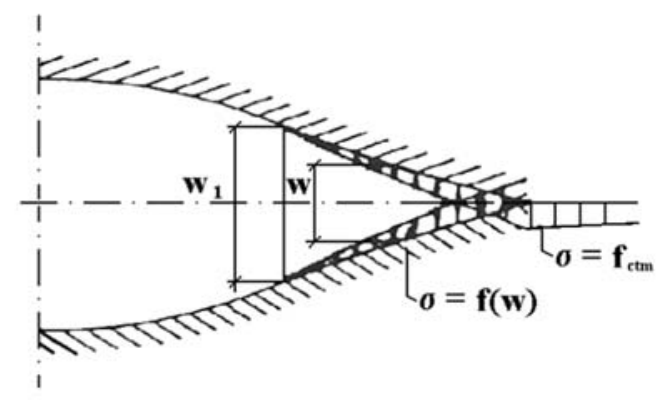

Figure 1: The essence of crack band model of tensile concrete.

In a crack bend model additional concrete fracture parameters should be determined. These parameters are:

- uniaxial tensile strength limit $\left(f_{c t}\right)$,

- fracture energy $\left(G_{F}\right)$,

- the shape of the stress-deformation diagram $(\sigma-\delta)$.

The stress-deformation properties of concrete are given by two curves: stress-strain $(\sigma-\varepsilon)$ and stress-crack opening curve $(\sigma-w)$, because after reaching the tensile strength, stress starts to decrease whereas deformation increases within the damage zone and decreases in the remaining part of a member - see Fig. 2. The value of the energy $G_{F}$ corresponds to the area under the curve $\sigma-w$.
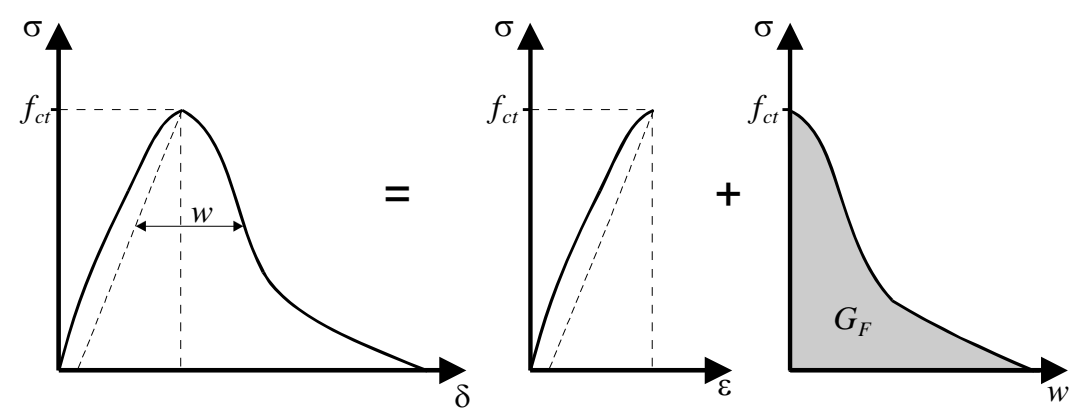

Figure 2: Stress-deformation diagram for concrete in tension. 
The decrease in stress under increasing deformation is called strain softening and it takes place in the narrow zone where the progressive microcracking appears - see Fig. 3 . The width of the active microcracking band, which is called the width of fracture process zone $\left(w_{c}\right)$, is the additional parameter taken into account when fracture in concrete is modelled as a smeared crack band.

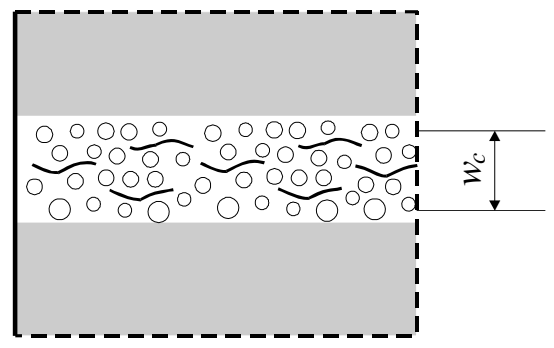

Figure 3: Fracture process zone width.

Recognizing and testing fracture parameters is of paramount importance when analyzing fracture process in concrete structures. The correct data of material's properties and adequate fracture model applied in numerical simulations influence final results. In the paper the findings reported in professional literature are summarized and obtained results of the own numerical simulation are reported in order to give a deeper knowledge on the role of aggregate on fracture processes in concrete structures. In particular the problem how the choice of the width of the fracture process zone influences the results of numerical calculations is discussed.

\section{METHODS OF TESTING CONCRETE FRACTURE PROPERTIES}

$\mathrm{M}$

aterial property values shall be determined from standardized tests performed under specified conditions. A conversion factor shall be applied where it is necessary to convert the test results into values which can be assumed to represent the behaviour of the material or product in the structure or the ground.

The procedure of making specimens for testing hardened concrete and the shape and dimensions of standardized specimens are described in the codes [2,3]. The general rule says that the size of specimen for testing concrete property should not be less than four times the maximum aggregate size. Therefore cubes 150/150/150 $\mathrm{mm}$ and cylinders $\phi 150 / 300 \mathrm{~mm}$ are recommended for concrete with the aggregate size up to $32 \mathrm{~mm}$. Cubes 100/100/100 $\mathrm{mm}$ can be used for testing concrete with the maximum aggregate size $16 \mathrm{~mm}$ and cubes 200/200/200 $\mathrm{mm}$ when the aggregate size is up to $63 \mathrm{~mm}$. The specimens which are used in testing concrete properties are shown in Fig. 4.

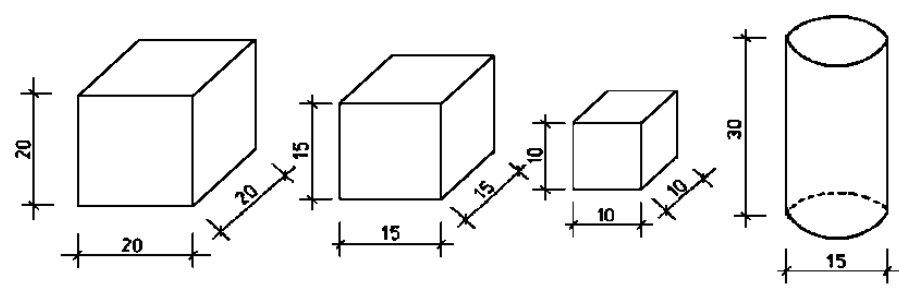

Figure 4: Specimens for testing concrete properties (dimensions in $\mathrm{cm}$ ).

The test procedure for determining the main concrete property - compressive strength is well known [4]. The compressive strength of concrete is tested in an axial compression test on standardized cylindrical or cubic specimens. The fact that a shape and sizes od specimens influence the compressive strength of concrete is well known. The parameter taken in design of concrete structure is characteristic compressive strength derived from values tested on cylinders $\phi 150 / 300 \mathrm{~mm}$. Therefore, conversion factors should be applied when compression strength is tested on other specimens: 


$$
f_{c, \text { cube } 15}=0.9 f_{c, \text { cub } 10}=1.05 f_{c, c u b e 20}=1.25 f_{c, \text { gl } / 15 / 30}
$$

The tensile strength of concrete should be tested in an axial tensile test. As it is not easy to perform a stable tension test, therefore the tensile strength of concrete is usually determined in a splitting tensile test and this test is described in the code [5] as a standardized test. For testing the splitting tensile strength of concrete, cylindrical specimens $\phi 150 / 300 \mathrm{~mm}$ are recommended, but cubic specimens are also available. It is pointed in [5] that the value of the splitting tensile strength also depends on the shape and dimensions of tested specimens. The tensile splitting strength tested on cubic specimens $150 / 150 / 150 \mathrm{~mm}$ is approximately $10 \%$ higher compering to the strength obtained on cylinders $\phi 150 / 300 \mathrm{~mm}$ and lower than strength tested on cubes $100 / 100 / 100 \mathrm{~mm}$. The uniaxial tensile strength of concrete should be calculated on the basis of the splitting tensile strength $f_{c t}=0.9 f_{c t, s p}$, as it is written in Eurocode 2 [6].

Main fracture parameters of tensile concrete should be determined in a deformation-controlled tensile test. Unfortunately, such a test is difficult to perform. For measurements of energy absorption, a three point bend test on a beam with a central notch has been proposed by RILEM Technical Committee 50 [7]. Such a test is recommended for testing fracture energy because it is much easier to perform it than a stable tensile test. Also some alternative methods of testing fracture energy can be found in the literature, for example the wedge-splitting test $[8,9]$, as yet they have not been standardized. The sizes of standard specimens recommended by RILEM [7] for testing fracture energy depend on a maximum aggregate size $D_{\max }$, according to Tab. 1 . Taking into account a significant effect of specimen's size on fracture energy values, the new recommendation as to fracture energy testing was proposed by RILEM [10]. In the modified method it is assumed to determine fracture energy on at least three different sizes beams with the notch. The dimensions of specimens also depend on aggregate granulation. The width $b$ and the depth $d$ of the tested beams must not be less than three times of maximum aggregate size whereas the notch width should not exceed 0.5 times the maximum aggregate size .

\begin{tabular}{ccccc}
\hline$D_{\max }[\mathrm{mm}]$ & Depth $d[\mathrm{~mm}]$ & Width $b[\mathrm{~mm}]$ & Length $L[\mathrm{~mm}]$ & Span $l[\mathrm{~mm}]$ \\
\hline $1 \div 16$ & $100 \pm 5$ & $100 \pm 5$ & $840 \pm 10$ & $800 \pm 5$ \\
$16.1 \div 32$ & $200 \pm 5$ & $100 \pm 5$ & $1190 \pm 10$ & $1130 \pm 5$ \\
$32.1 \div 48$ & $300 \pm 5$ & $150 \pm 5$ & $1450 \pm 10$ & $1385 \pm 5$ \\
$48.1 \div 64$ & $400 \pm 5$ & $200 \pm 5$ & $1640 \pm 10$ & $1600 \pm 5$ \\
\hline
\end{tabular}

Table 1: Sizes of specimens for testing fracture energy [7].

In experimental investigation on fracture energy of concrete which were performed on different size specimens for concretes with different maximum size of aggregate it has been found that fracture energy increases with an increase of the maximum aggregate size and with an increase of the specimen size. For example, in Kleinschrodt and Winkler experiment [11] the doubling of the maximum gravel aggregate from $D_{\max }=8 \mathrm{~mm}$ to $D_{\max }=16 \mathrm{~mm}$ caused an increase of the $G_{F}$ value by $25 \%$. Whereas $60 \%$ higher fracture energy was obtained in concretes with limestone aggregate size up to $16 \mathrm{~mm}$ than up to $8 \mathrm{~mm}$ in tests performed by Golewski [12].

These findings have been applied not only in RILEM recommendations according to sizes of beams for fracture energy tests but they are also reflected in analytic formulas for estimating fracture energy. For example, the formula (2) proposed by Bažant and Oh [13] can be mentioned.

$$
G_{F}=\left(3.1 \times 10^{-6} f_{c t}+2.57\right) f_{c t}^{2} \frac{D_{\max }}{E_{c}}
$$

where $G_{F}$ is given in $\left[\mathrm{Nm} / \mathrm{m}^{2}\right], f_{t t}$ and $E_{c}$ in $[\mathrm{Pa}]$, and $D_{\max }$ in $[\mathrm{m}]$.

In case of the lack of testing values of fracture energy, $G_{F}$ can be calculated according to CEB-FIP Model Code [14] where the maximum aggregate size was also taken into account in the formula (3).

$$
G_{F}=\alpha_{F} f_{c}^{0.7} \quad\left[\mathrm{Nm} / \mathrm{m}^{2}\right],
$$


where $\alpha_{F}$ depends on $D_{\max }$ and is equal $\alpha_{F}=4 ; 6 ; 10$ when $D_{\max }=8 ; 16 ; 32 \mathrm{~mm}, f_{c}$ is compressive strength of concrete in [MPa].

The determination of the width and the length of the fracture process zone is even more difficult experimental problem and there are no standard methods of their measurement. The findings which have been reported in several scientific papers suggests that the ratio $w_{c} / D_{\max }$ ranges from 1 to 5 . Mostly the relation $w_{c}=3 D_{\max }$ is recommended as a good approximation in numerical analyses, for example by Bažant and Oh [13], and Zhang and Wu [15].

Interesting experiments were performed by Otsuka and Date [16]. To investigate the behavior of the fracture process zone in concrete, they used X-rays with contrast medium and three-dimensional acoustic emission techniques. Experiments were carried out on differently-sized specimens made by concrete with different maximum aggregate size 5, $10,15 \mathrm{~mm}$. When comparing fracture process zone traced from X-ray films, the researchers have found that width and the length of fracture process zone are closely related each to the other. With the increase of maximum aggregate size, the width of fracture process zone increases whereas the length of fracture process zone decreases - see Fig. 5.

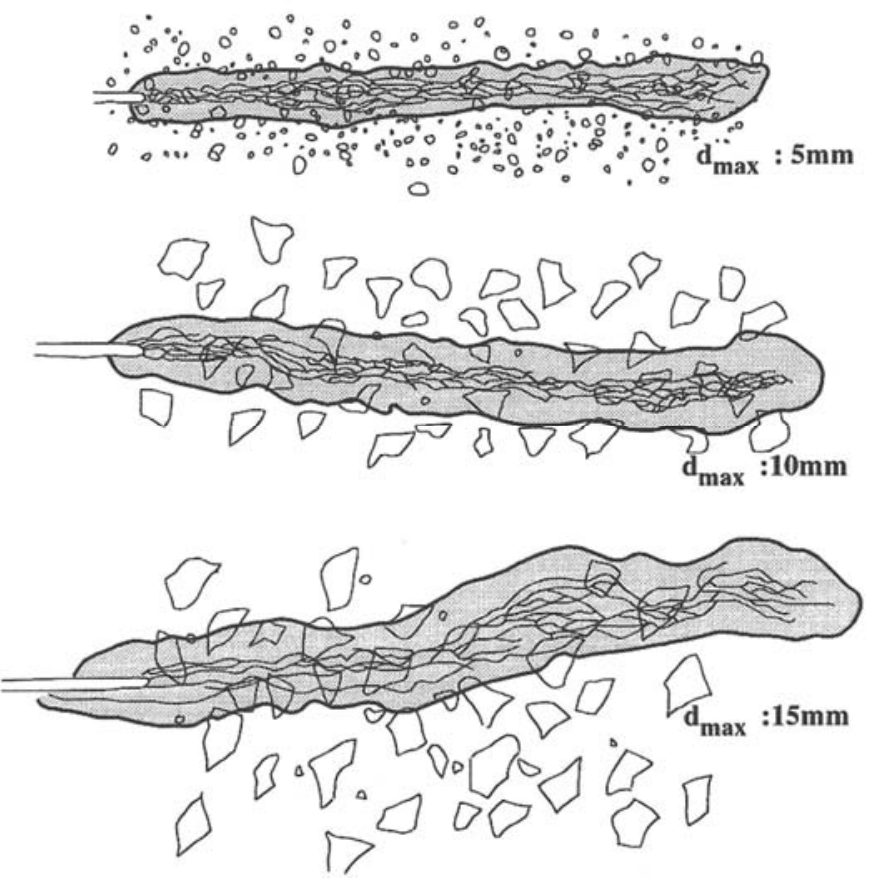

Figure 5: Fracture process zone traced from X-rays films [16].

The influence of aggregate granulation on testing methods according to compressive and tensile strength, as well as fracture energy is deeply recognized. As already pointed out, there are no standard methods to determine the width of fracture process zone experimentally. The experimental finding suggest that the width of fracture process zone is affected by maximum aggregate size but there are no consensus how. The question arises on how to model the width of fracture process zone when performing numerical simulations of concrete structures.

\section{NUMERICAL INVESTIGATION}

10 analyze how the choice of the width of the fracture process zone influences the results of numerical calculations in the case of concrete beams, the numerical simulation has been performed using the commercial program ALGOR, which is based on Finite Element Method (FEM). Then, the obtained results of calculations have been compared with the authors' own experimental data.

When performing the experimental investigation, three concrete beams were tested. The beams had a rectangular cross section of the width $b=0.15 \mathrm{~m}$ and the height $b=0.30 \mathrm{~m}$. The total length of the beams was $L=3.00 \mathrm{~m}$ whereas the span was $l=2.70 \mathrm{~m}$. The beams were tested in four-point bend test, but the reversed type of loading was used. Beams were loaded symmetrically by two concentrated forces, which were applied from bottom towards the top by hydraulic 
jacks. The procedure of controlling displacement was used during the test in order to slow down the cracking process. Beam geometry and the static scheme of the test specimen are shown in Fig. 6.

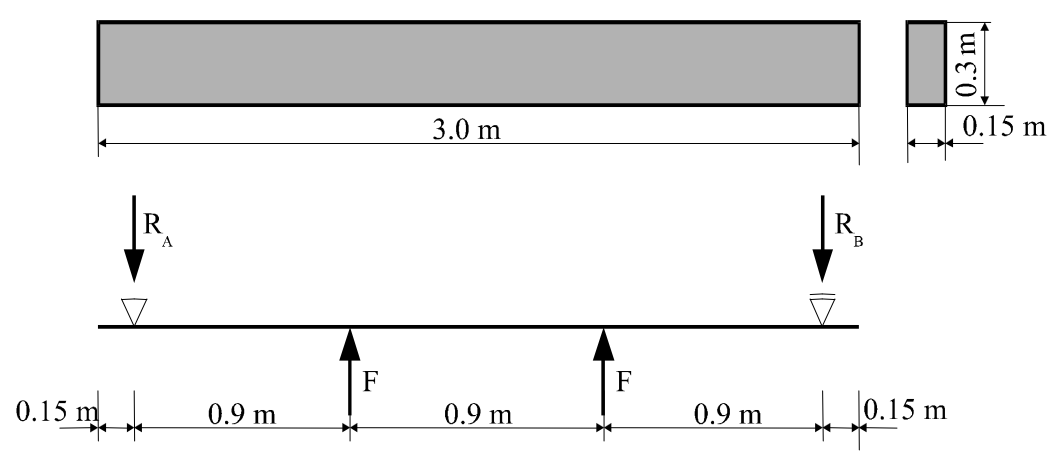

Figure 6: Static scheme of a tested beam.

The basic mechanical properties of concrete were tested by standard methods and evaluated statistically. They are listed below:

- the tensile strength $f_{\text {ctm }}=1.5 \mathrm{MPa}$,

- the compressive strength $f_{\text {cm }}=20.5 \mathrm{MPa}$,

- the modulus of elasticity $E_{c m}=22 \mathrm{GPa}$,

- the fracture energy $G_{F}=83 \mathrm{Nm} / \mathrm{m}^{2}$.

When preparing the concrete mixture, a gravel aggregate was used with the maximum size $D_{\max }=32 \mathrm{~mm}$.

During the test, concrete strains were recorded on two levels in tension and compression zone of the beam, by Huggenberger's gauge. The measured concrete strains were than used to compare them with numerical findings. The wider description of performed experiments has been presented in [17].

The FEM-analysis was performed on one half of the concrete beam corresponding to the test specimen since the fourpoint test is symmetrical. The brick and truss elements were used in beam modelling, brick elements for bulk material and truss element for concrete in the fracture process zone. The bulk material of the beam was chosen as linear elastic one and only in the region of fracture zone the concrete was modelled as nonlinear material. The fracture process zone was modeled in the region where the force was applied as it was the cross section of the biggest bending moment due to reversed static scheme and the influence of a self-weight. To analyze the influence of the width of the fracture process zone on the results of numerical calculations different widths were taken at modelling this zone: $w_{c}=5 ; 10 ; 20 ; 26.5 ; 50$ and $100 \mathrm{~mm}$. The finite element mesh for the analyzed beam with the width of fracture process zone $w_{c}=10 \mathrm{~mm}$ is shown in Fig. 7. The numerical simulation was performed to analyze other scientific problems as well [18,19].
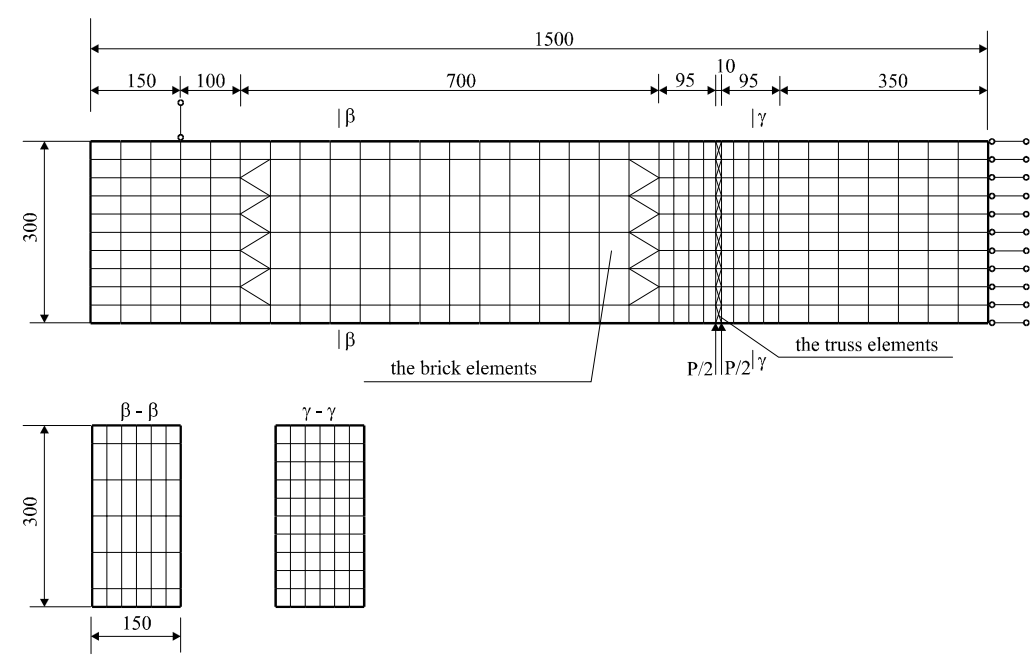

Figure 7: The mesh used in a FEM simulation [18]. 
The same material properties as those obtained during the experiment were used in numerical simulation. The crack band model was applied. The stress-deformation diagrams were simplified by bilinear relations according to the proposition given in CEB-FIP Model Code [20] - see Fig. 8.
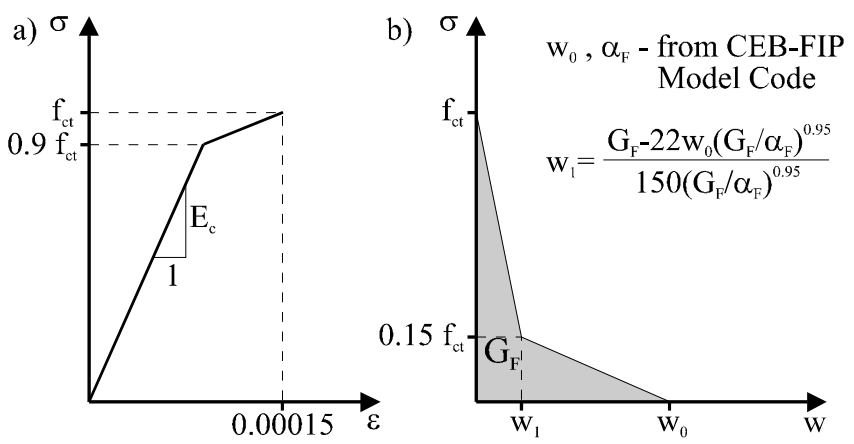

Figure 8: Model of tensile concrete recommended by CEB-FIP: stress-strain diagram for uncracked concrete (a), stress-crack opening for cracked concrete (b) [20].

When performing the numerical simulations, the dislocations of nodes and stress components along three axes of the global coordinate system were obtained. In order to verify the model of tensile concrete applied in the numerical simulation, experimental results were compared with the results of numerical calculations. The elongations measured in the concrete beams on the base $250 \mathrm{~mm}$ long by Huggenberger's gauge in tension and compression zone were juxtaposed with the adequate elongation from the numerical simulation. The bases were situated in the middle of the beam's span, in the region outside the fracture process zone. From the comparison which is presented in Fig. 9, a satisfactory agreement between experimental measurements and numerical results can be observed. It confirms that concrete in the bulk material outside the active fracture zone can be described by bilinear stress-strain relation presented in Fig 8.a.
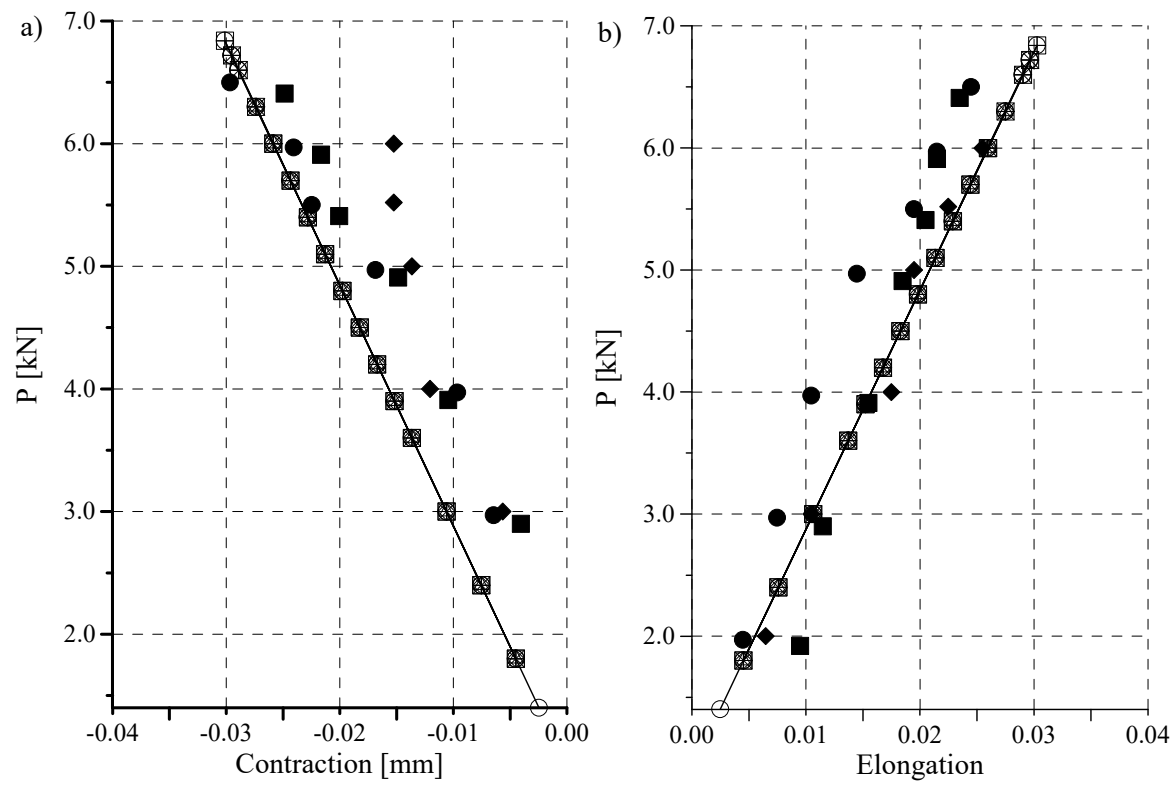

Figure 9: Elongation in compression zone (left) and tension zone (right) - comparison of experimental measurements and numerical results.

Furthermore, diagrams of normal stress distribution along the fracture process zone for analyzed beams have been made. To compare the obtained diagrams for concrete beams with different $w_{c}$, they have been juxtaposed at the same level of loading (Fig. 10). When analyzing the diagrams presented in Fig. 10, some differences in numerical results can be seen in 
dependence of the width of fracture process zone. We can observe that at applied load $F=6 \mathrm{kN}$ in the simulation with fracture process zone $w_{c}=50$ and $100 \mathrm{~mm}$, normal stress at upper stage of tension zone reaches the tensile stress whereas in case of width of fracture process zone 5, 10, 20 and 26.5 the normal stress start to decrease and the tensile strength was reached at a lower loading stage. It can be concluded that the greater the width of fracture zone, taken in FEMcalculation, the less intensive strain softening of tension concrete.

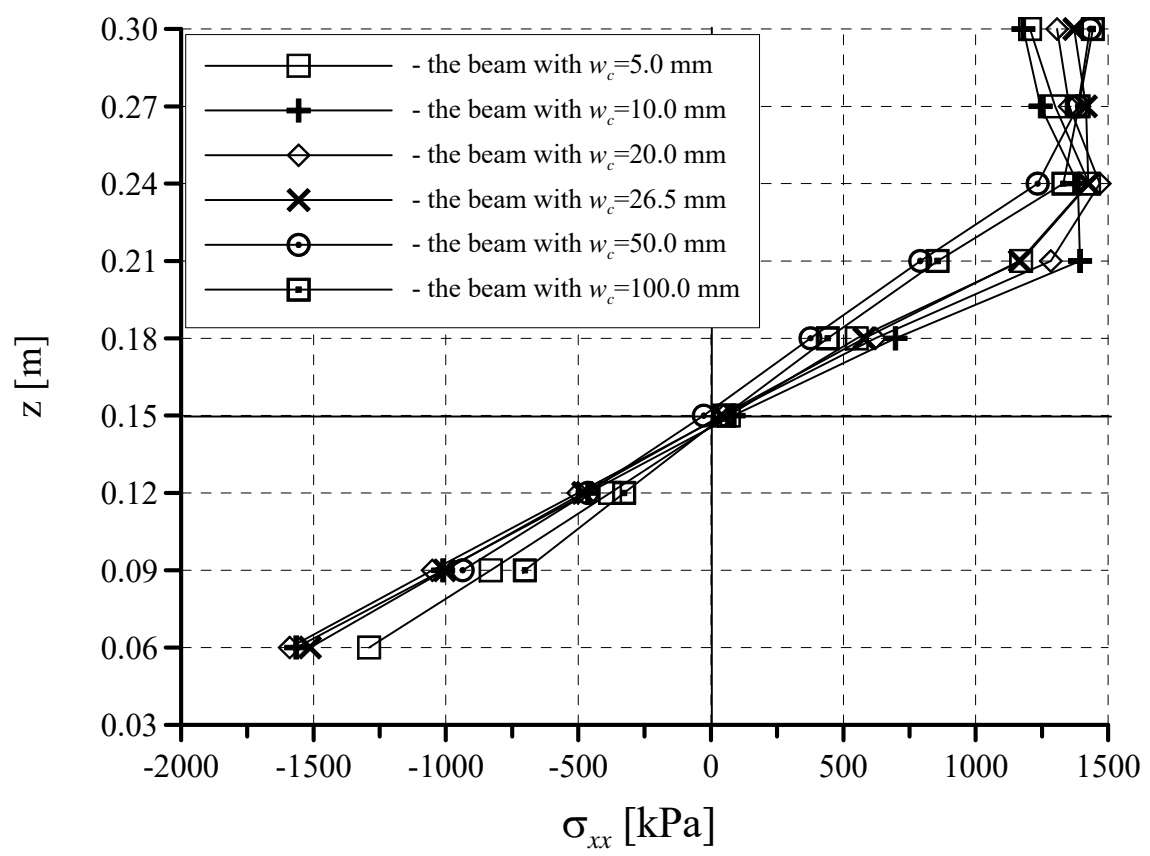

Figure 10: Comparison of normal stress distribution in the cross section of crack band in the simulated beam with different fracture process zone width $w_{c}$ at the load stage $F=6 \mathrm{kN}$ (note that tension zone is in a upper part of a cross section).

The performed numerical simulation has confirmed that nonlinear model for tensile concrete should be used when analyzing failure of concrete structures. Microcracks in the region of a cross section with the highest internal forces tend to join leading to formation and propagation of the failure crack. But the crack does not appear in the moment when stress reaches the tensile strength of concrete. There are still some ligaments which cause a slower crack formation and we can observe the descending branch in stress distribution diagram obtained in numerical simulation - see Fig 10 . But the numerical analysis has clearly showed the differences in calculation results resulting by the width of the fracture process zone taken in FEM-calculations. The energy which is necessary for crack formation is cumulated in the narrow region of fracture process zone. The performed numerical simulation has given the evidence how important is to apply correct fracture parameters, in particular the width of fracture process zone, in numerical calculations.

\section{CONCLUSIONS}

$\mathrm{O}$ $\mathrm{n}$ the basis of the review of scientific works presented in the paper, it may be concluded that the influence of aggregate granulation on fracture parameters of concrete exists. In case of tensile strength and fracture energy of concrete this problem has been wider described. There are no definite conclusions as far as the influence of aggregate size on the width of the fracture process zone is concerned. The performed numerical analysis confirms that the width of the fracture process zone has an influence on the FEM results. The proper choice of this parameter during the numerical calculation is a condition of obtaining correct results performed by finite element method.

When explaining the influence of aggregate graining on fracture parameters of concrete, in particular fracture energy and the width of fracture process zone, the non-homogeneous internal structure of hardened concrete should be considered. Concrete is intensively microcracked before loading in so called virgin state. Additionally, several air pores and water is left in concrete matrix. All these facts cause a non-uniform distribution of local fracture energy. Furthermore, the presence of large size aggregate grains prevents the crack from opening and results in wider fracture process zone. In normal strength 
concrete the crack surrounds aggregate grains during the process of crack formation and propagation. This phenomenon can be observed when analyzing a crack path obtained in splitting tensile test - see Fig. 11.

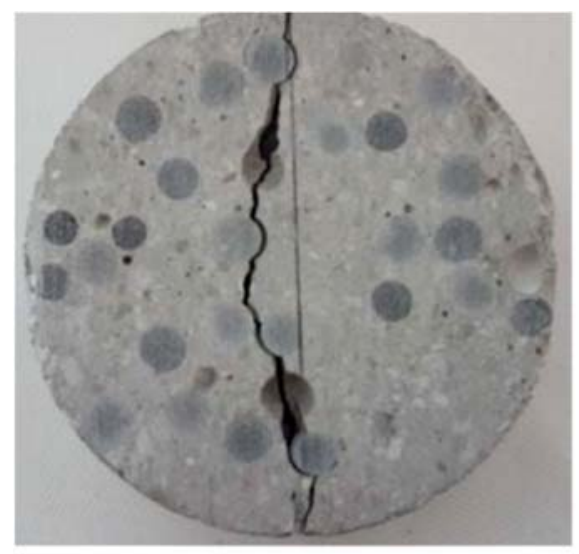

Figure 11: Crack's path obtained during the splitting tensile test [21].

It would be valuable to find general standard rules for determining all fracture parameters of concrete. In particular the influence of the maximum aggregate size on the width of fracture process zone requires systematic investigations. In further works, the analysis of cracking mechanisms in concrete should be performed on both micro- and macro-level.

\section{ACKNOWLEDGMENTS}

his work was supported by Lublin University of Technology.

\section{REFERENCES}

[1] Hillerborg, A., Modeer, M., Petersson, P. E. (1976) Analysis of Crack Formation and Crack Growth in Concrete by Means of Fracture Mechanics and Finite Elements. Cement and Concrete Research, 6, pp. 773-782 .

[2] EN 12390 Testing hardened concrete. Part 1: Shape, dimensions and other requirements of specimens and moulds. CEN, Brussels.

[3] EN 12390: 2019, (2019). Testing hardened concrete. Part 2: Making and curing specimens for strength tests. CEN, Brussels.

[4] EN 12390: 2019, (2019). Testing hardened concrete. Part 3: Compressive strength of test specimens. CEN, Brussels.

[5] EN 12390: 2019, (2019). Testing hardened concrete. Part 6: Tensile splitting strength of test specimens. CEN, Brussels.

[6] EN 1992-1-1: 2004, (2004). Eurocode 2. Design of concrete structures - general rules and rules for buildings. CEN, Brussels.

[7] Rilem Draft Recommendation, (1985). Determination of the fracture energy of mortar and concrete by means of three-point bent tests on notched beams. Matériaux et Constructions. 18(106), pp. 258-290.

[8] Fernández-Canteli, A. et al., (2014). Determining fracture energy parameters of concrete from the modified compact tension test. Frattura ed Integrità Strutturale, 30, pp. 383-393. DOI: 10.3221/IGF-ESIS.30.46

[9] Korte, S., et al. (2014). Static and fatigue fracture mechanics properties of self-compacting concrete using three-point bending tests and wedge-splitting tests. Construction and Buildings Materials, 57, pp. 1-8.

DOI: 10.1016/j.conbuildmat.2014.01.090

[10] Rilem Draft Recommendation, (1990). Size-effect method for determining fracture energy and process zone size of concrete. Matériaux et Constructions. 23(138), pp. 461-465. 
[11] Kleinschrodt, H. D. and Winkler, H. (1986). The Influence of the Maximum Aggregate Size and the Size of Specimen on Fracture Mechanics Parameters. Fracture Toughness and Fracture Energy of Concrete, edited by F. H. Wittmann, Elsevier Science Publishers B. V., Amsterdam, pp. 391-402.

[12] Golewski, G. J. (2007). Influence of $D_{\max }$ on Fracture Mechanics Parameters of Concrete Made of Limestone Aggregate at Three Point Bending (in Polish). Budownictwo i Architektura, 1, pp. 5-16.

[13] Bažant, Z. P. and Oh, B. H. (1983). Crack Band Theory for Fracture of Concrete. Matériaux et Constructions, 16(193), pp. 155-177.

[14] CEB-FIP Model Code 1990 Bulletin d'information No. 19.

[15] Zhang, D., Wu, K. (1999) Fracture process zone of notched three-point-bending concrete beams. Cement and Concrete Research, 29, pp. 1887-1892. DOI: 10.1016/S0008-8846(99)00186-6.

[16] Otsuka, K., Date, H. (2000). Fracture process zone in concrete tension specimen. Engineering Fracture Mechanics. 63, pp. 111-131. DOI: 10.1016/S0013-7944(99)00111-3.

[17] Słowik, M. (2019). The analysis of failure in concrete and reinforced concrete beams with different reinforcement ratio. Archive of Applied Mechanics, 89, pp. 885-895. DOI: 10.1007/s00419-018-1476-5.

[18] Słowik, M. (2010). Numerical analysis of the width of fracture process zone in concrete beams. Computational Materials Science, 50, pp.1347-1352. DOI: 10.1016/j.commatsci.2010.05.013

[19] Słowik, M., Stroeven, P., Akram, A. (2020). Crack mechanism in concrete - from micro to macro scale. Budownictwo i Architektura, 19(4), pp. 55-65. DOI: 10.35784/bud-arch.2147.

[20] CEB-FIP Model Code 1990. Bulletins d'information. No 196.

[21] Benkemoun, N., et al. (2017). 3-D mesoscale simulation of crack-permeability coupling in the Brazilian splitting test. International Journal for Numerical and Analytical Methods in Geomechanics 42(1), pp. 1-20. 